\title{
Techno-economic Feasibility Analysis of Photovoltaic Charging Station for Electric Boats in Sabangko Island
}

\author{
B. D. Indradjaja ${ }^{1 *}$, Ing. B. Ramadhani ${ }^{2}$, Phil. M. Günther ${ }^{3}$, P. Gunawan ${ }^{1}$ \\ ${ }^{1}$ Swiss German University, Jl. Jalur Sutera Bar. No. Kav 15, 15143 Banten \\ ${ }^{2}$ GIZ - Energy Program, Jl. HOS Cokroaminoto No. 91, 10310 Jakarta \\ ${ }^{3}$ University of Oldenburg, Carl-von-Ossietzky-Str. 9-11, 26129 Oldenburg, Germany \\ Received 13 September 2019; Accepted 8 November 2019 \\ Available online 28 February 2020
}

\begin{abstract}
Indonesia is the largest archipelago in the world. There are thousands of islands that are located far away from the grid that needs access to electricity. As a result, PV mini-grids have been installed in many remote islands. However, most of these PV mini-grids are under-utilized producing large amounts of unused excess energy. Since most of the inhabitants of these remote islands depend on fishing for their livelihoods, an idea was proposed to use excess energy from a PV mini-grid to power electric boats. This paper presents a techno-economic feasibility analysis of a PV charging station for electric boats using Sabangko Island in Makassar as an exemplary location. A detailed analysis of the existing system shows that there is enough excess energy to charge several boat batteries. The economic analysis shows that the LCOE of the project is quite low relative to other off-grid projects and the price of renting and charging a battery is still affordable.
\end{abstract}

Keywords: PV, charging station, electric boat, battery, energy modelling

\section{Introduction}

Indonesia is a large archipelago of 17,508 islands stretching over 5,000 kilometers across Southeast Asia and Oceania. The island geography of the country poses a challenge for services in and transport to outlying provinces (Asian Development Bank, 2016). Since Indonesia is a country dominated by water, marine vessels or boats are very important as a means of transport and fishing. People living near the shore are usually fishermen including traditional fishermen that use small boats. However, due to a lack of infrastructure and distribution channels, fuel can be scarce in remote islands when there is bad weather. Furthermore, until recently fuel prices in remote islands are more expensive than in Java (Indonesia Investments, 2016). Therefore, alternatives such as electric motor-powered boats are a promising idea.

As of early 2018, EBTKE has installed over 600 PV mini-grids across the country according to REMAP Indonesia, a map showing locations of PV mini grids (Energizing Development, 2018). However, through the inspections conducted by GIZ, it has been discovered that many of these systems are underutilized and produce large amounts of excess energy that are currently being dumped. Due to these circumstances, an idea emerged to use excess energy from these PV mini-grids to power a charging station for electric boat batteries. Only the excess energy will be used this purpose and it should not disturb the main usage of the mini-grid that is to electrify the households.

However, the amount and hours in which the system produce excess energy in a day is limited. Thus, the number of electric boat batteries that the system can charge is also limited. Therefore, the amount and hours of excess energy needs to be investigated to know how many if any boat batteries can be charged from the system and whether or not the charging will be affordable.

* Corresponding author
E-mail address: bjornderian@gmail.com 


\section{Research Methods}

\subsection{Location}

The studied site is on Sabangko Island in South Sulawesi. South Sulawesi has a notably strong maritime presence which has been historically known as a centre for seaborne trade being a crossroad of local and inter-insular coastal movements. In addition to that, sea cucumbers, also known as teripang, are abundant in the region. Local people have been exporting and trading sea cucumbers since the 17th century further reinforcing its strong maritime culture (Schwerdtner Máñez \& Ferse, 2010).

Sabangko is an island north-west of the capital city of South Sulawesi, Makassar. It was granted a 20 $\mathrm{kWp}$ solar mini grid system by the government in 2017. It has 56 residential homes and 10 public facilities all equipped with electricity. This island was chosen as a test site because its inhabitants are either seaweed farmers or fishermen. The current usage is only for lighting, short time usage of TV and phone charging. By installing solar-powered boats, electricity can be used productively.

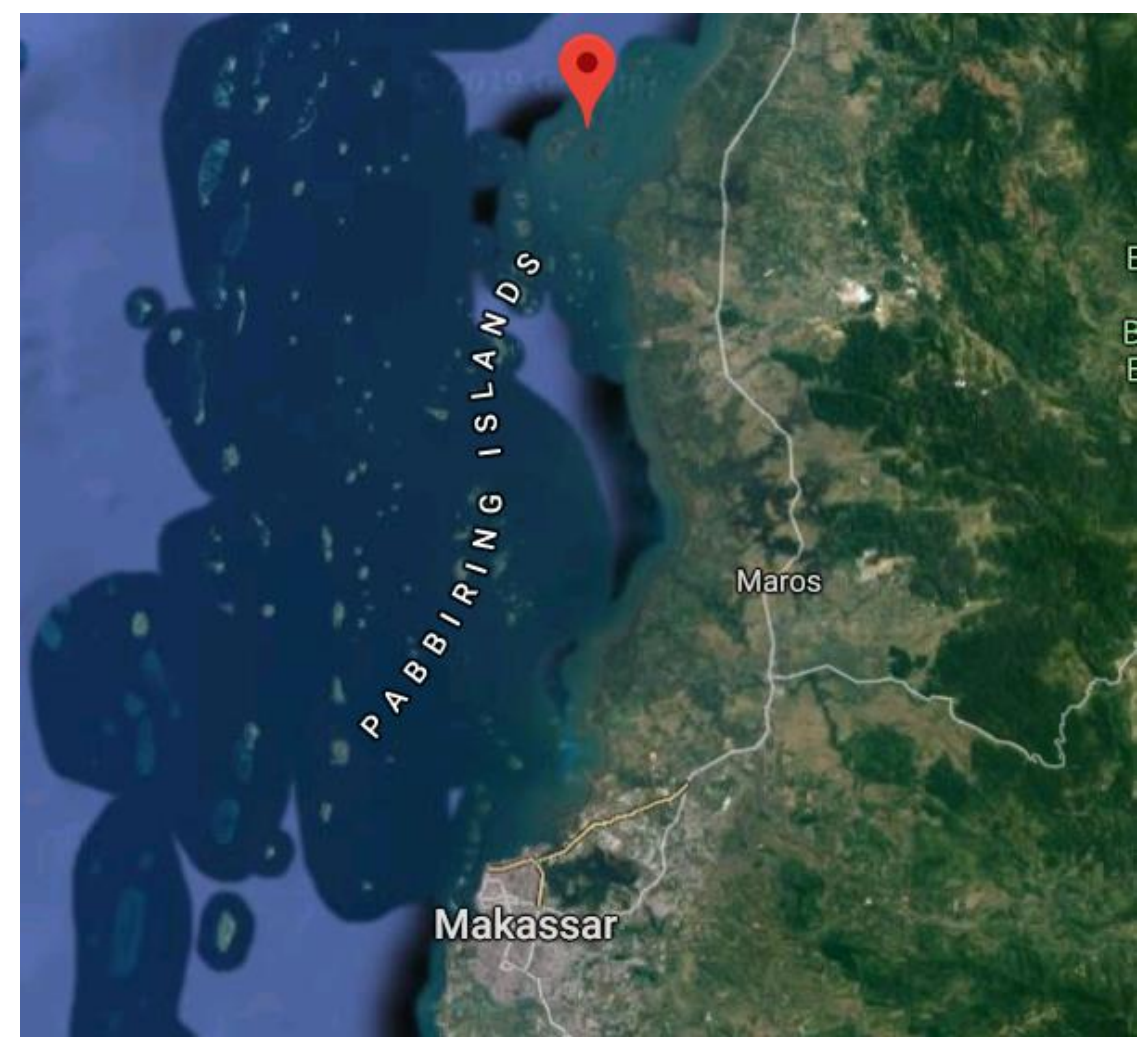

Figure 1. Sabangko island satellite view.

\subsection{Data Collection}

Firstly, four main data is collected that is: data regarding the mini grid components in Sabangko island, the energy generation profile, the load profile and lastly the battery charging. Afterwards an energy model is created using the data to find when and how many batteries that can be charged from the excess energy in the mini-grid.

On the island of Sabangko, every household has been given access to electricity. However, each family unit is limited to $500 \mathrm{Wh}$ per day. There are 56 family units and 10 public facilities meaning that there are 66 consumers. The figure below shows the typical load profile in an off-grid island in Sulawesi estimated from GIZ's data obtained from a previous inspection that they did on several mini-grids in 
the Sulawesi area and collecting raw data from the inverters. It starts at midnight and proceeds until the next day, also note that the data has already been scaled for 66 users.

Since there is no Pyranometer or energy production data logger in the location, meteorological data is used to model the production of the PV system. Data sources are from NASA MERRA (Rienecker et al., 2011) and CM-SAF's SARAH dataset (Müller et al., 2015). Raw data in form of direct and diffuse radiation is directly acquired, on top of that ambient temperature is also provided. Global irradiation from Sabangko island on a module with a tilt angle of 15 degrees facing north and ambient temperature data is shown in the figures below.

Apart from those data primary and secondary data regarding fishermen behaviour, modelling equations, technical specifications and component costs were collected from multiple sources including facilitators, company reports, and the internet.
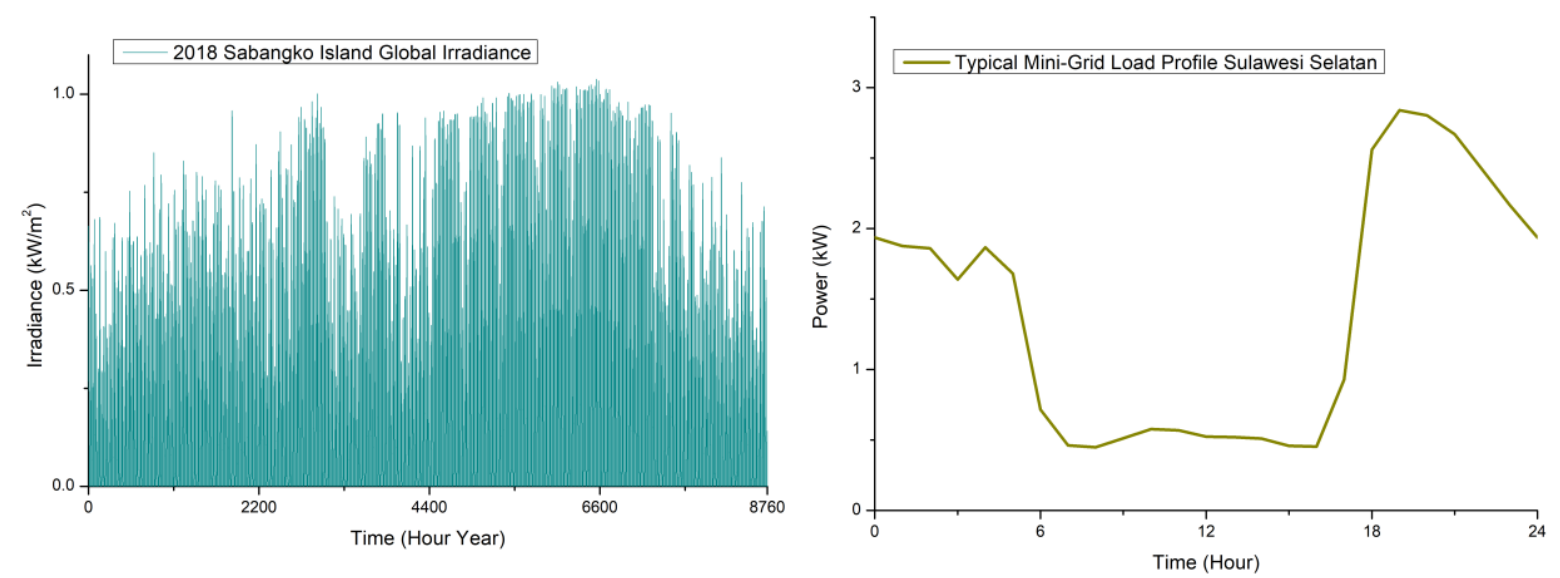

Figure 2. Irradiance profile (left) and load profile (right) of Sabangko Island.

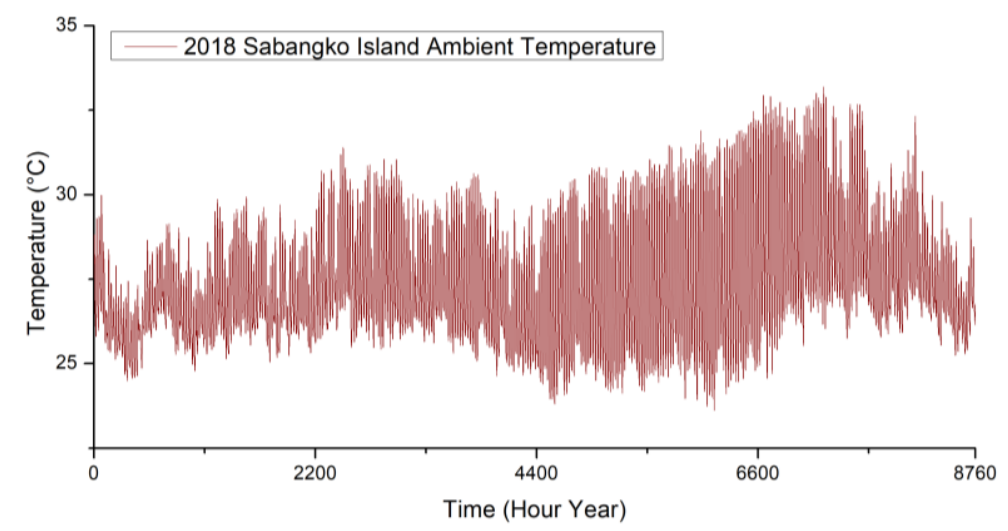

Figure 3. Ambient temperature in Sabangko Island.

\subsection{Modelling}

The current model simulates the off-grid photovoltaic system as composed of the following parts: photovoltaic array, DC / AC converter, electrical load connection, solar electric boat charging station and an energy storage device. The model is created on an excel spreadsheet by using the above beforementioned data and equations from multiple sources (Belmili, Haddadi, Bacha, Almi, \& Bendib, 2014; Bhandari, Poudel, Lee, \& Ahn, 2014; Hamad \& Alsaad, 2010; Ross, G., \& Jr., 1976). The full list of equations and modelling tool can be seen in Appendix 1 and 2 respectively. 


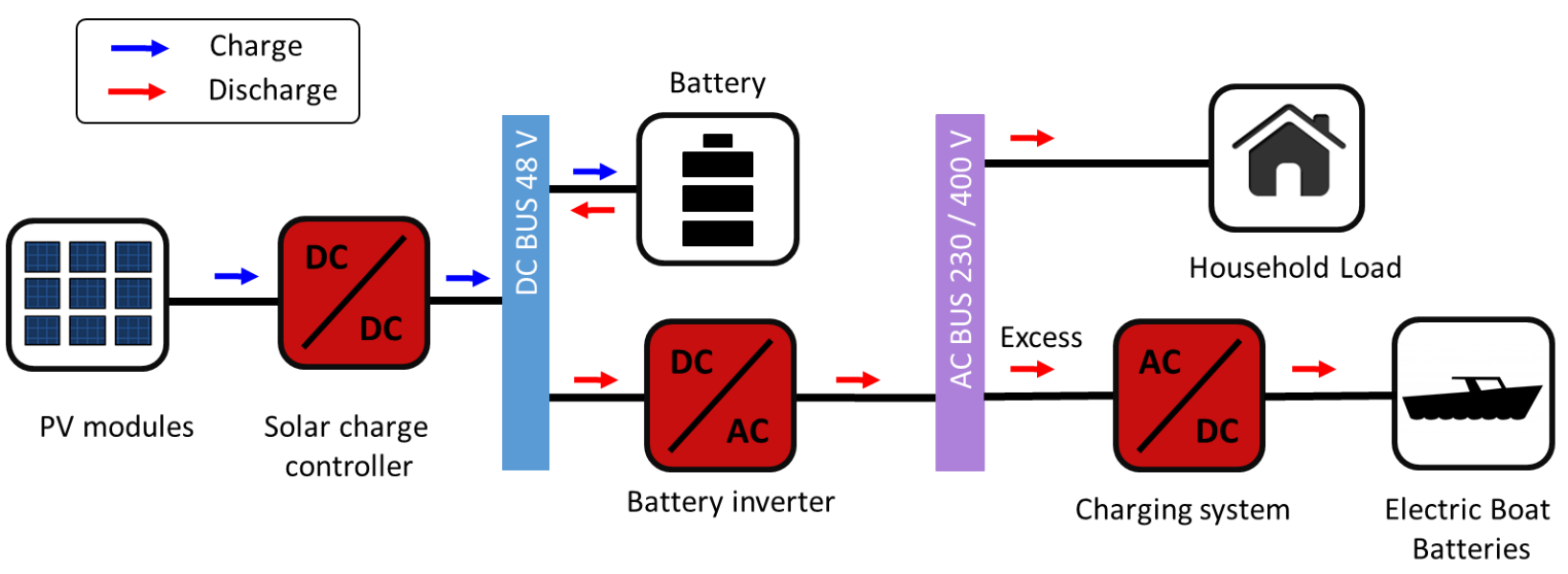

Figure 4. Sabangko island mini-grid system configuration.

\subsection{Economic Analysis}

Economic analysis will be done using the levelized cost of electricity method or LCOE. Darling's approach calculates the LCOE by assessing the total average lifetime costs divided by the total energy output shown in Equation 1 (Darling, You, Veselka, \& Velosa, 2011).

$$
L C O E=\frac{I_{O}+\sum_{t=1}^{n} \frac{O M_{t}+F_{t}}{(1+R)^{t}}}{\sum_{t=1}^{n} \frac{E_{t}}{(1+r)^{t}}}
$$

Where $O M_{t}$ are operation and maintenance expenditures, $E_{t}$ is generated electrical energy, $F_{t}$ are fuel expenditures, $I_{o}$ are initial investment costs, $r$ is the real discount rate (without inflation) and $n$ is the expected lifetime of the project. $R$ is the nominal discount rate (with inflation) which is given using fisher's equation (Barro, 1997) where $i$ is the inflation rate:

$$
R=\frac{1+r}{1+i}-1
$$

\subsection{Electric Motor, Boat Battery and Mini-Grid Specification}

\subsubsection{Pilot Electric Motor Specification}
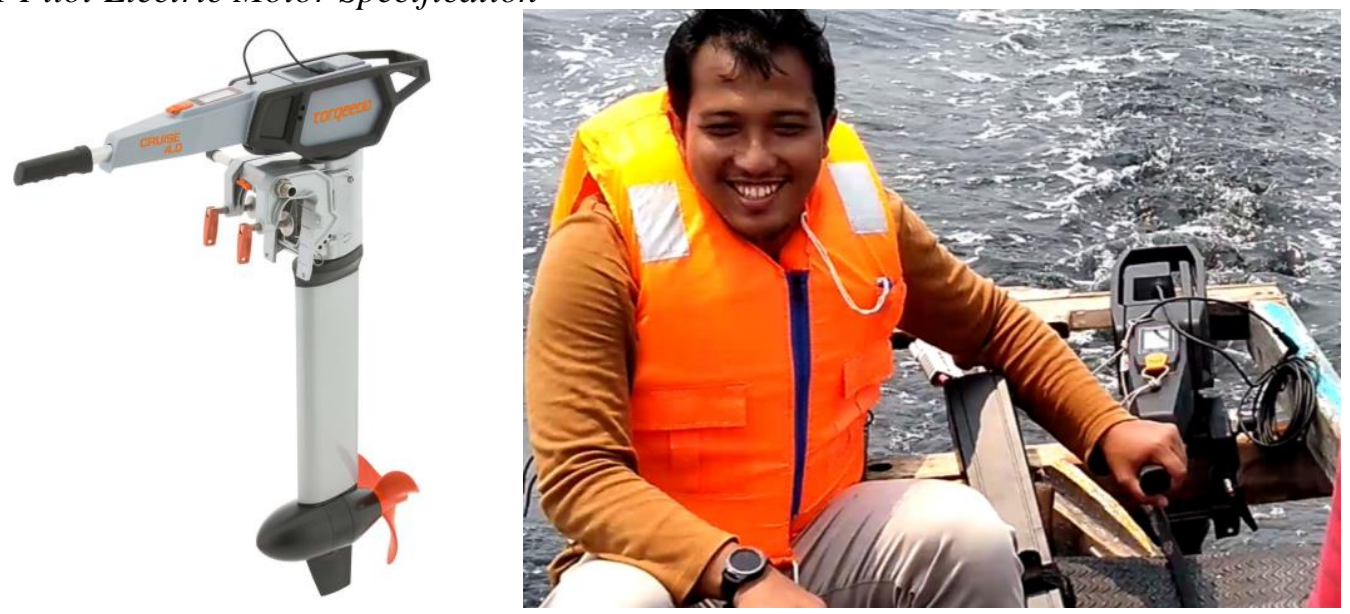

Figure 5. Pilot electric motor product illustration (left) and operation during testing (right). 
Table 1. Pilot electric motor specification obtained through testing (Ariwibowo, Gunawan, Ramadhani, \& Günther, 2019).

\begin{tabular}{cc}
\hline Specification & Remarks \\
\hline Electric motor & $4000 \mathrm{~W} / 48 \mathrm{~V}$ DC motor \\
Energy Consumption & $14.8 \mathrm{kWh} / 100 \mathrm{~km}$ \\
Maximum Speed & $9.4 \mathrm{~km} / \mathrm{h}$ \\
Typical Trip Distance & $12 \mathrm{~km}$ \\
Typical Trip Consumption & $1.78 \mathrm{kWh}$ \\
\hline
\end{tabular}

\subsubsection{Pilot Boat Battery Specification}

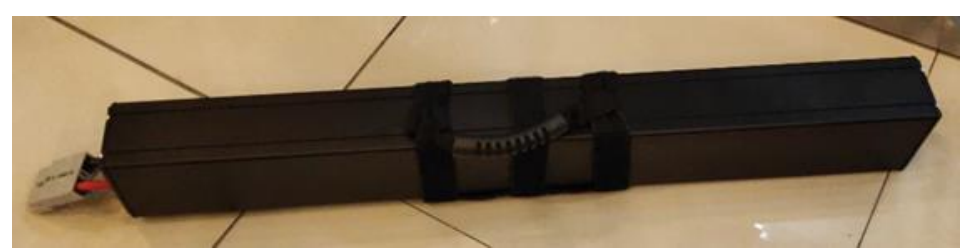

Figure 6. Photograph of pilot Li-Ion $1.35 \mathrm{kWh}$ battery

Table 2. Pilot Boat Battery Specification

\begin{tabular}{cc}
\hline Specification & Remarks \\
\hline Battery Type & Lithium - Ion \\
Capacity & $1.35 \mathrm{kWh}$ \\
Charging time to full & $1 \mathrm{~h}$ \\
Price & IDR $14,000,000$ \\
Lifetime (approx.) & 10 years \\
\hline
\end{tabular}

\subsubsection{PV Mini-grid Specification}

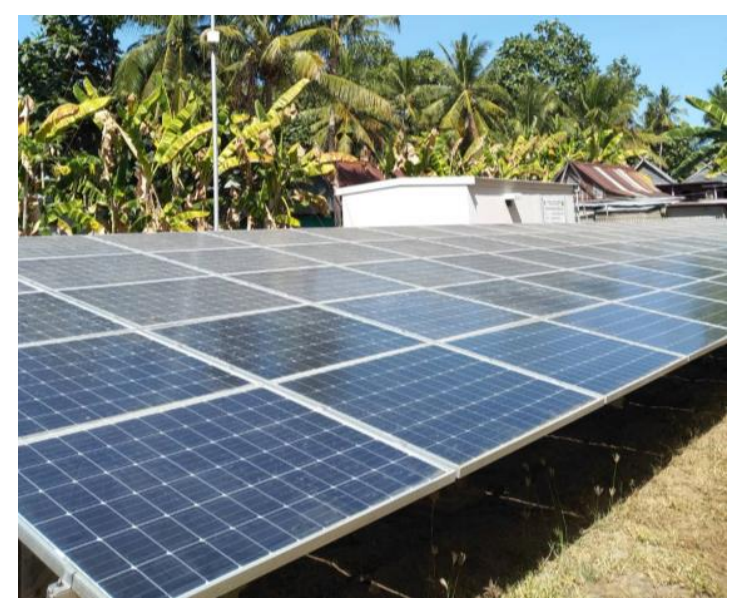

Figure 7. Photo of Sabangko Island PV system 
Table 3. Sabangko Island PV-Mini Grid specification

\begin{tabular}{cc}
\hline Specification & Remarks \\
\hline Peak Power & $20 \mathrm{kWp}$ \\
Efficiency & $18 \%$ \\
PV Energy Storage & Lead Acid $192 \mathrm{kWh}$ \\
System Configuration & DC Coupling \\
Inverter and Charge & Victron \\
Controller Brand & \\
\hline
\end{tabular}

\section{Results and Discussion}

\subsection{Modelling Results}

\subsubsection{Current Energy Allocation}

The figure on the left below shows the daily energy generation from the PV system. The Y axis represents the energy in $\mathrm{kWh}$ and the $\mathrm{X}$ axis represents the day of the year. The figure on the right is a pie chart that shows where the total energy generated from the PV is allocated over one year. Each part of the pie chart represents a possible way that energy from the PV system can be utilised.

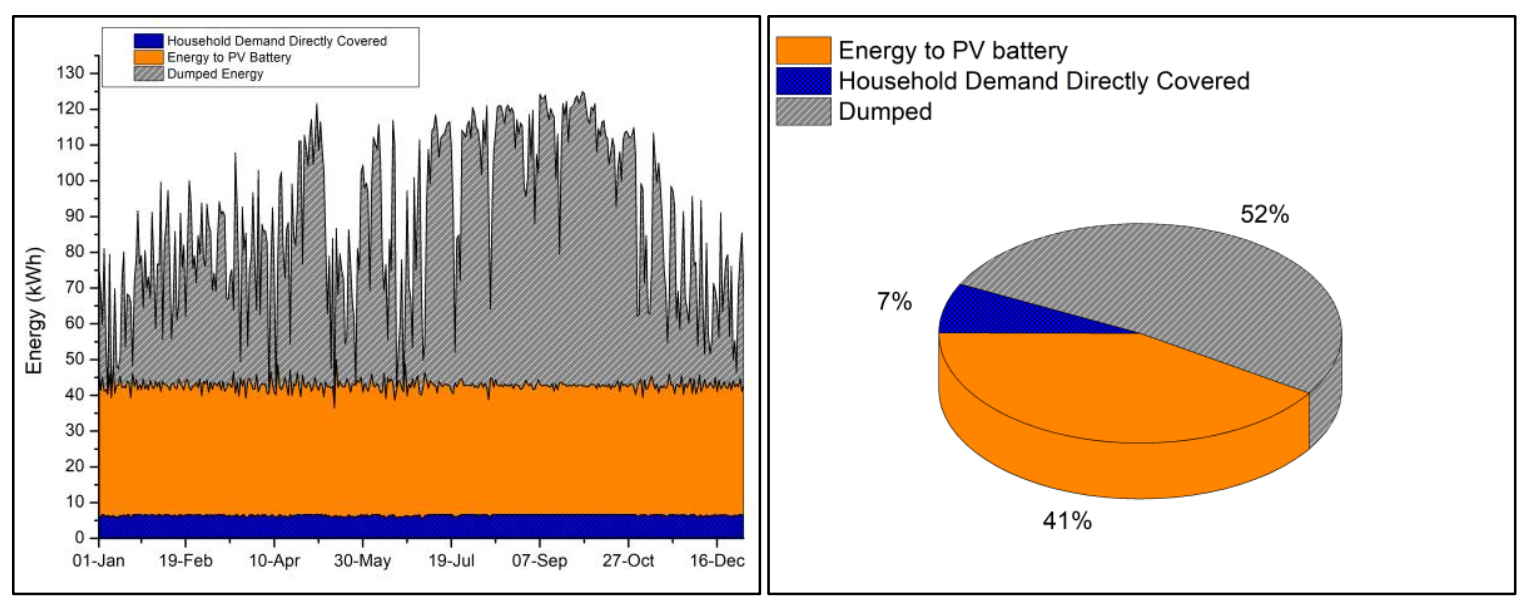

Figure 8. Area chart (left) and pie chart current system energy allocation

As can be seen in the figure above, there are three pathways in which energy generated from the PV system can go to: household demand directly covered which is defined as when there is demand from the electricity users and there is energy generated from the PV system to fulfil it. energy to PV battery which is when the energy storage used to fulfil household demand at night is not full and the energy generated from the PV system is used to charge it and lastly dumped energy is the rest of the energy that is not used. More than half of the energy is dumped in the current situation.

The energy generation in Figure 8 follows the irradiation profile and additionally there is the temperature factor affecting it. The household demand directly covered and the energy that goes into the PV storage is typically constant over the year because of the energy limiter that limits electricity usage to around $500 \mathrm{Wh}$ per day. It can be observed that there is much more energy allocated to charge the PV battery compared to the household demand directly covered, this is because the electrical users use more energy at night than during the day meaning more potential for excess energy. 
The two figures show a large amount of dumped energy from the system which can be possibly utilized by the solar powered electric boats. However, the dumped or excess energy from the system is very much not constant, this might present a problem regarding the consistency to fully charge the boat batteries over the year. This problem will be discussed in more detail in the next section.

\subsubsection{Consistent number of batteries charged}

The figure on the left below is a graph from the model showing the total number of batteries that can be charged using excess energy over the day for one year. As can be seen below there is a high number of variations over the year. The battery charged each day can vary from a maximum of 54 batteries to none.
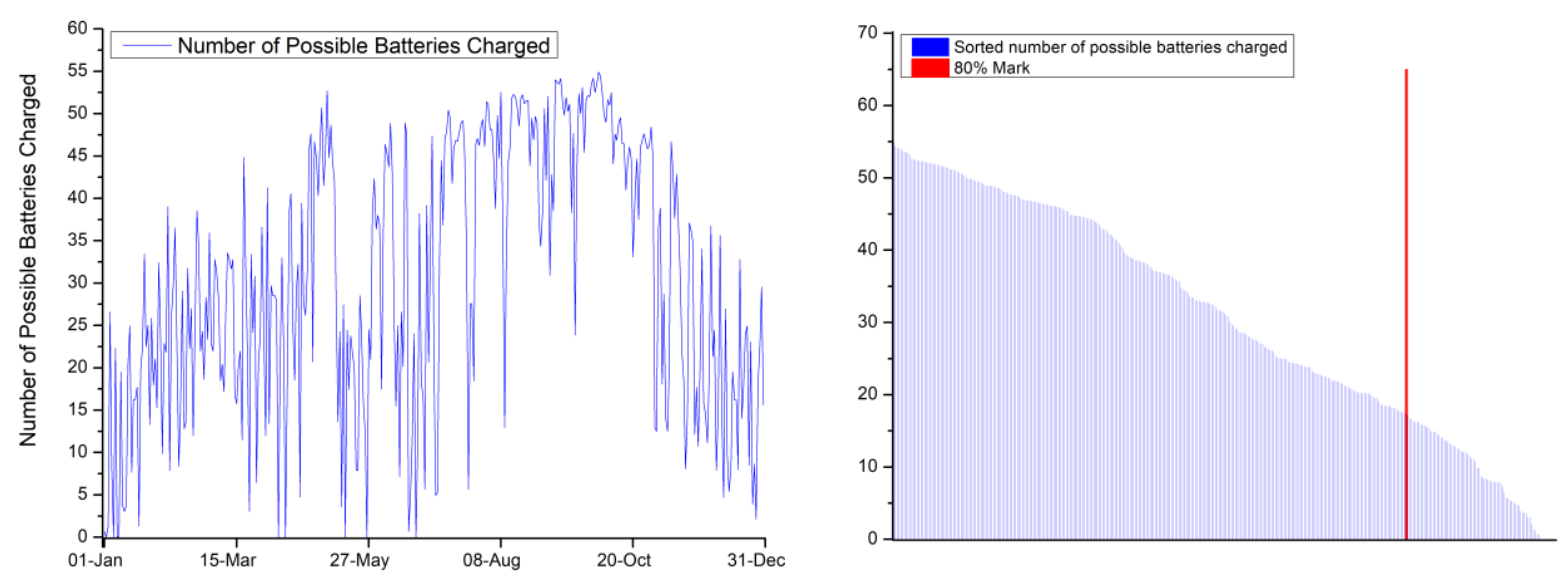

Figure 9. Number of possible batteries charged according to the day of the year (left) and sorted number of possible batteries charged in the year (right).

This is a problem since if for example, one fisherman uses two battery, and there are 20 fishermen using electric boats, they can only use the full capacity of their batteries in the dry season, and during the rainy season; when excess energy is less; their batteries would run short. Hence, the number of batteries that the system can consistently charge over the year should be found. It was decided that $80 \%$ of the time is a reasonable value. Consequently, the figure on the right was created by sorting from the days with the highest number of batteries charged to the days with the lowest number of batteries charged and a line was drawn on the $80 \%$ mark. On this line, 17.41 batteries are charged which means that the excess energy is sufficient to charge 17 batteries consistently over the year.

\subsubsection{Sufficient Charger Power}

Choosing the sufficient charger power is an important task when designing this system because too much power will increase costs but too little power means that the charger will not be fast enough to accommodate the charging of batteries to full in just a few hours of excess energy.

By inserting an additional parameter to the model; specifically, the charger power to limit the amount of power that can be used to charge the batteries, the number of batteries charged over the year according to the charger power is now able to be found. Ergo, a sensitivity analysis was then created with the open parameter charger power with an increment of $1 \mathrm{~kW}$ for the purpose of finding the sufficient charger power.

Figure 10 shows the batteries charged per day according to the charger power installed. The upper whisker shows the maximum number and the lower whisker shows the minimum number. The line and cross inside the boxes show the median and mean respectively. The box shows the inter-quartile-range (IQR) which is the difference between the upper quartile (Q3) and the lower quartile (Q1) and it is also where $50 \%$ of the data lies. 


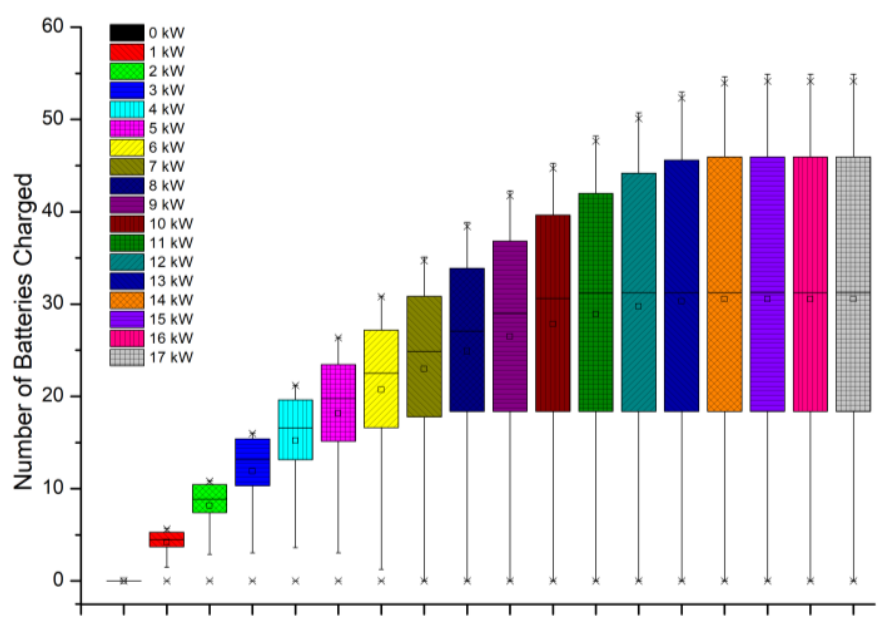

Figure 10. Boxplot of number of batteries charged according to charger power.

The most interesting part from the box and whisker plot below is that the maximum, $3^{\text {rd }}$ quartile and average number of batteries charged per day starts increases by a large margin and starts to stagnate at around $10 \mathrm{~kW}$ and after $13 \mathrm{~kW}$ there is no visible increase anymore.

However, the $1^{\text {st }}$ quartile of batteries charged starts to stagnate at $6 \mathrm{~kW}$ and does not increase anymore after $8 \mathrm{~kW}$, earlier than other deciding parameters (maximum, mean, $3^{\text {rd }}$ quartile). This means that even though more batteries are charged per day with more charger power; at least $25 \%$ of the time, the number of batteries charged does not change after $8 \mathrm{~kW}$. Hence revealed that increasing the charger power after a certain optimum only increases the spread of the values by increasing the number of batteries charged during high excess energy days but does not help with the days when excess energy is low. Therefore, the optimum charger power for the system is $8 \mathrm{~kW}$.

\subsubsection{Energy Allocation with Solar Powered Electric Boats}

An additional load of 17 batteries limited by $8 \mathrm{~kW}$ charger was added to the model. The results were then reiterated and presented in this section. The two figures below show the new energy allocation after installing the new task of charging electric boat batteries.
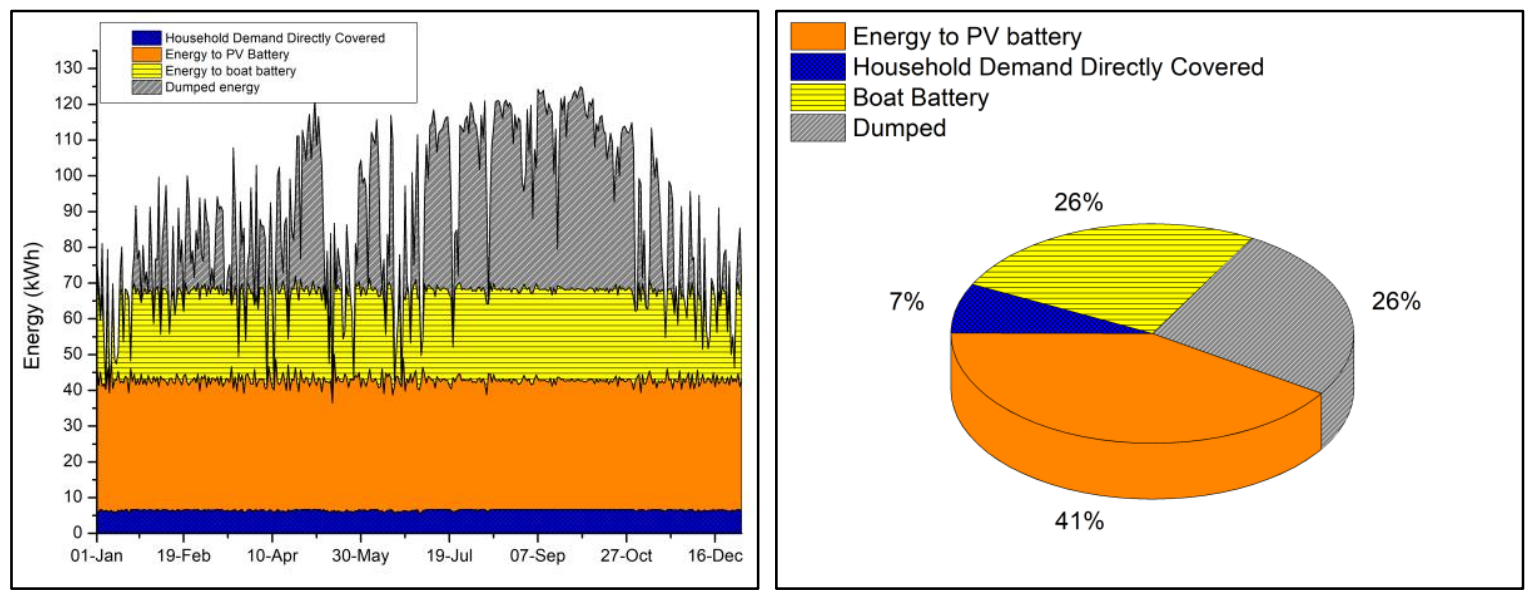

Figure 11. Area chart (left) and pie chart (right) of the system energy allocation after installing boat battery charging system.

The figure above shows the total allocation of energy generated by the PV system. The total amount of energy generated by the system is $32,430 \mathrm{kWh}$. The amount of energy allocated to charge the PV battery storage is $13,265 \mathrm{kWh}$. The amount of household demand directly covered by the PV system during the 
day is $2,376 \mathrm{kWh}$. Energy used for charging the boat battery assuming that all 17 batteries are charged and used every day is $8,377 \mathrm{kWh}$. The rest $8,410 \mathrm{kWh}$ of energy is still dumped.

The total amount of dumped energy has been reduced by half from $52 \%$ to $26 \%$ because of the solar powered electric boat task. This still leaves quite a large amount of excess energy which is dumped at $8,410 \mathrm{kWh}$ per year or around $23 \mathrm{kWh}$ per day. The still present large amount of excess energy, presents another opportunity for other productive uses of the excess energy. Especially those that don't necessarily need a stable supply over the whole year e.g. desalination plants, ice makers, ground water pumping, etc.

From this result, we can state that there is enough excess energy in the system to charge a considerable amount of batteries and technically from the amount of energy available, this project is technically feasible.

\section{Economic analysis results}

\subsection{Cost and Prices}

Table 4 summarizes the relevant data of the components the complete prices of replacement costs. The price of the boat battery charging system was estimated using the price of a programmable power supply that was chosen as the most suitable product which is the Meanwell DPU series, that costs around Rp. $3,000,000$ per $\mathrm{kW}$. The ideal charger power is $8 \mathrm{~kW}$ then the price was marked up to Rp. $30,000,000$ to include other costs of the system such as sensors, switches, cables, controllers, etc ("DRP-3200 / DPU3200 3200W Power Supplies - Mean Well | Mouser Indonesia,” n.d.).

Table 4. Lifetime, price, usage percentage and share price of key hardware.

\begin{tabular}{|c|c|c|c|c|}
\hline Components & $\begin{array}{l}\text { Lifetime } \\
\text { (years) }\end{array}$ & Price & $\begin{array}{l}\text { Usage } \\
\text { Percentage }\end{array}$ & Share Price \\
\hline PV Battery Storage & 8 & $\begin{array}{c}508,000,0 \\
00\end{array}$ & $0 \%$ & 0 \\
\hline Battery inverter & 10 & $\begin{array}{c}200,000,0 \\
00\end{array}$ & $35 \%$ & $70,000,000$ \\
\hline Solar charge controller & 10 & $\begin{array}{c}69,000,00 \\
0\end{array}$ & $35 \%$ & $24,150,000$ \\
\hline MCB, Fuse & 5 & $1,500,000$ & $35 \%$ & 525,000 \\
\hline $\begin{array}{c}8 \mathrm{~kW} \text { Boat Battery Charging } \\
\text { System }\end{array}$ & 10 & $\begin{array}{c}30,000,00 \\
0\end{array}$ & $100 \%$ & $30,000,000$ \\
\hline
\end{tabular}

In view of the fact that the charging system also puts a burden on the original PV system, the replacement costs were differentiated based on the share of energy each respective task uses which is defined as the 'usage percentage'. The usage percentage is found using the amount of energy used by the charging system divided the total produced energy found in Figure 11, which is $26 \%$. Since the dumped energy is not included in the calculation, the usage percentage then becomes $35 \%$.

The inverter, solar charge controller and $\mathrm{MCB}$ replacement costs are included because for energy to be used by the charging system, it needs to go through all those components. The PV battery storage usage percentage is considered $0 \%$ because the boat charging system only utilizes excess energy and does not interact with the PV storage at all. The boat battery charging system usage percentage is $100 \%$ because 
the household electric load does not utilize it at all. The PV module itself is not included in the replacement cost owing to the fact the charging system will not accelerate the aging of the PV modules.

\subsection{Charging and Battery Renting Business}

Charging and Battery Renting business is a scenario where the fishermen are not willing to buy batteries and but are willing to buy an electric motor This result will be more realistic and practical in a sense because fishermen living in remote islands are more likely to pay a fee for service option compared to buying batteries in cash (Bhattacharyya, 2011). Therefore, to find the price of such a service, the yearly cash flow for the project was created over 20 years using an inflation and discount rate of $3 \%$ and $5 \%$ respectively. The full cash flow projection can be seen in Appendix 3.

The results are then summarized in the table below and calculated to find the price of charging and renting the battery to the fishermen.

Table 5. Electric boat battery charging and renting business price calculation.

\begin{tabular}{lll}
\hline Component & \multicolumn{1}{c}{ Cost } & \\
\hline Total Operator Wages & $82,876,000$ & IDR \\
Shared Replacement Costs & $78,982,000$ & IDR \\
Other Operational Expenditures & $24,673,000$ & IDR \\
Charging system investment Cost & $30,000,000$ & IDR \\
17 Batteries investment cost & $238,000,000$ & IDR \\
Charging system and Batteries Replacement cost & $221,113,000$ & IDR \\
& & \\
Total NPV Costs & $675,644,370$ & IDR \\
Total NPV Energy Generated & 99,788 & kWh \\
& & \\
LCOE & Rp. 2,256/ & kWh \\
Renting and charging price & Rp. 6,770 / & Battery \\
& $\$ 0.48 /$ & Battery \\
\hline
\end{tabular}

LCOE-wise (around $\$ 0.16 / \mathrm{kWh}$ ), this project shows promise because compared to typical off grid PV projects the LCOE are usually higher at the range \$0.20-0.28 per kWh (Huld, Jäger-Waldau and Szabó, 2014; Lai and McCulloch, 2016; Micangeli et al., 2017)

Additionally, according to thestudy by Belzowski and Green (2013), the biggest cost over the lifetime of a diesel motor is the cost of buying fuel and that comparing between an electric and diesel motor through fuel costs (in the electric motor case the price of charging a battery) can already give a good estimate on which would be more economically attractive.

Based on a survey we did on the island; on average the fishermen spend Rp. 50,000 for fuel on every trip. Compared to the cost of renting one, two or even three batteries buying fuel is much more expensive. This shows the fishermen will be able to afford charging and renting batteries and this project based on fuel costs is economically feasible. 


\section{Conclusion}

This chapter consists of conclusions, recommendations on future works based on the findings of this research. The results of this study can be used as a foundation or tool in the development of solar powered off-grid charging stations for electric boats in the remote islands of the Makassar and other isolated areas in Indonesia or the world, where sufficient solar energy resources are available.

\section{Conclusion}

The main objective of this study is to determine whether or not an electric boat charged using excess energy from solar photovoltaic panels is technically and economically feasible. Primary and secondary data were taken from facilitators, company reports, and the internet. A model was created using modelling equations and results were then analysed to find how many boats can be supported by the system. Afterwards, the price of the electricity was determined and the costs compared to a typical diesel motor. Using the results from Sabangko island, some conclusions can then be drawn: The total energy generated by the PV system in Sabangko island is $32694 \mathrm{kWh}$ per year and the excess energy is $16789 \mathrm{kWh}$ per year. After using the system to charge e-boat batteries, half of the dumped energy is then used productively. The project is technically feasible because current PV system in Sabangko island can support $17 \mathrm{Li}$-ion $1.35 \mathrm{kWh}$ batteries and the optimum nominal power of the charger is $8 \mathrm{~kW}$. The LCOE to charge the batteries is found to be Rp. 2,282 can be considered cheap when compared between other PV mini-grids and the price of renting and charging batteries Rp. 6,770 is still affordable for the fishermen. Hence this project is economically feasible.

\section{Future Work}

This thesis has investigated the feasibility of retrofitting of excess energy from a PV system to charge electric boat batteries. Based on the findings of this thesis, there are some recommendations for future work:

1. Implementation, monitoring and evaluation of the charging station.

2. Socio-economic analysis to look into the effects of implementing such a system on the fishermen and other stake holders such as fuel vendors.

3. Further analysis of the stand-alone PV charging station to know whether using long term storage system to ensure a stable supply throughout the year can be economically attractive or not.

4. Creating a sustainable business plan that is financially attractive for investors yet still affordable for the fishermen while allowing smooth integration into the community.

\section{Acknowledgments}

This work was supported by GIZ Indonesia. 


\section{References}

Ariwibowo, T., Gunawan, P., Ramadhani, B., \& Günther, M. (2019). Techno-Economic Feasibility Analysis of using Electric Outboard Motor for Artisanal Fisher in Indonesia.

Asian Development Bank. (2016). Indonesia: Energy Sector Assessment, Strategy, and Road Map.

Barro, R. J. (1997). Macroeconomics. Retrieved from https://mitpress.mit.edu/books/macroeconomics-fifth-edition

Belmili, H., Haddadi, M., Bacha, S., Almi, M. F., \& Bendib, B. (2014). Sizing stand-alone photovoltaic-wind hybrid system: Techno-economic analysis and optimization. Renewable and Sustainable Energy Reviews, 30, 821-832. https://doi.org/10.1016/j.rser.2013.11.011

Bhandari, B., Poudel, S. R., Lee, K.-T., \& Ahn, S.-H. (2014). Mathematical modeling of hybrid renewable energy system: A review on small hydro-solar-wind power generation. International Journal of Precision Engineering and Manufacturing-Green Technology, 1(2), 157-173. https://doi.org/10.1007/s40684-014-0021-4

Bhattacharyya, S. C. (2011). Review of Alternative Methodologies for Analysing Off-Grid Electricity Supply. SSRN Electronic Journal. https://doi.org/10.2139/ssrn.1909257

Darling, S. B., You, F., Veselka, T., \& Velosa, A. (2011). Assumptions and the levelized cost of energy for photovoltaics. Energy and Environmental Science, 4(9), 3133-3139. https://doi.org/10.1039/c0ee00698j

DRP-3200 / DPU-3200 3200W Power Supplies - Mean Well | Mouser Indonesia. (n.d.). Retrieved June 23, 2019, from https://www.mouser.co.id/new/meanwell/mean-well-drp-3200-dpu3200/\#Bullet-2

Energizing Development. (2018). RE-MAP Indonesia. Retrieved June 17, 2019, from http://www.remap-indonesia.org/\#

Hamad, A. A., \& Alsaad, M. A. (2010). A software application for energy flow simulation of a grid connected photovoltaic system. Energy Conversion and Management, 51(8), 1684-1689. https://doi.org/10.1016/j.enconman.2009.09.036

Indonesia Investments. (2016). One Fuel Price Policy Indonesia, Higher Operational Costs Pertamina $\mid$ Indonesia Investments. Retrieved from https://www.indonesiainvestments.com/news/todays-headlines/one-fuel-price-policy-indonesia-higher-operationalcosts-pertamina/item7295?

Müller, R., Pfeifroth, U., Träger-Chatterjee, C., Trentmann, J., Cremer, R., Müller, R., ... Cremer, R. (2015). Digging the METEOSAT Treasure-3 Decades of Solar Surface Radiation. Remote Sensing, 7(6), 8067-8101. https://doi.org/10.3390/rs70608067

Rienecker, M. M., Suarez, M. J., Gelaro, R., Todling, R., Bacmeister, J., Liu, E., ... Woollen, J. (2011). MERRA: NASA's Modern-Era Retrospective Analysis for Research and Applications. Journal of Climate, 24(14), 3624-3648. https://doi.org/10.1175/JCLI-D-11-00015.1

Ross, G., R., \& Jr. (1976). Interface design considerations for terrestrial solar cell modules. Retrieved from https://ntrs.nasa.gov/search.jsp?R=19780027121

Schwerdtner Máñez, K., \& Ferse, S. C. A. (2010). The History of Makassan Trepang Fishing and Trade. PLoS ONE, 5(6), e11346. https://doi.org/10.1371/journal.pone.0011346 


\section{APPENDICES}

\section{Appendix 1. Energy model formulas}

\section{PV Output}

The model calculates the energy generated by the PV module in a linear energy conversion. Since the Sabangko Island system is DC-coupled, the formula will be different from an AC-coupled system, hence DC power will first be calculated. The model simulates with hour-time step hence the equation directly gives energy $E_{P V}$ instead of power and is given by (Belmili et al., 2014):

$$
E_{P V}=G_{i r} A_{p v g} \eta_{p v g}
$$

where $\eta_{p v g}$ is PV generation efficiency, $A_{p v g}$ is PV generator area $\left(\mathrm{m}^{2}\right)$, and $G_{i r}$ is the global solar irradiation in tilted module plane $\left(\mathrm{W} / \mathrm{m}^{2}\right)$. The efficiency of the conversion $\eta_{p v g}$ is further defined as (Bhandari et al., 2014):

$$
\eta_{p v g}=\eta_{r} \eta_{p c}\left[1-\beta\left(T_{c}-T_{c r e f}\right)\right]
$$

where $\eta_{p c}$ is the charge controller efficiency; $\eta_{r}$ is the reference module efficiency; $\beta$ is the temperature coefficient $0.45 \%$ per ${ }^{\circ} \mathrm{C}$ (Mau \& Jahn, 2006; Skoplaki \& Palyvos, 2009). ; $T_{c \text { ref }}$ is the reference cell temperature in ${ }^{\circ} \mathrm{C}$, defined by the STC (Standard Test Conditions) as $25^{\circ} \mathrm{C} ; T_{c}$ is the solar cell temperature.

Ross, G. and Jr. (1976) states that the solar cell temperature can be estimated using a model which is also the simplest and most widely used model:

$$
T_{c}=T_{a}+k G_{i r}
$$

where $T_{a}$ is the ambient temperature; the slope $k$ is also called the Ross coefficient which describes the temperature rise of a PV cell with increasing irradiance.

Afterwards the inverter is used to convert this DC output to AC voltage; which is used to power most electrical appliances; to cover the electrical demand from the household connections. The inverter output energy $E_{i n v, A C}$ is then calculated using the following equation (Hamad and Alsaad, 2010):

$$
E_{i n v, A C}=\eta_{i n v} E_{i n v, D C}
$$

where $E_{i n v, D C}$ is the inverter input DC energy, i.e. the energy the PV generated calculated using Equation (3) and $\eta_{i n v}$ is the inverter efficiency. 


\section{Demand}

There will be two types of demand that will be differentiated. "Directly covered" means that when there is demand present, there is enough PV energy to fulfil the demand directly. "Not directly covered" means that when there is a demand, the PV does not fulfil it directly, but is taken from the energy storage. Hence, at a given moment the demand directly covered by the system $E_{s}$ is given by Equation (7):

$$
E_{S}=\min \left(E_{d}, E_{i n v, A C}\right)
$$

where $E_{d}$ is the total demand asked of the system. If the AC output is higher than the demand, the demand directly covered will be the full demand. If the AC output is smaller than the demand, the demand directly covered will be the AC output. The formulas for demand not yet covered $E_{n c}$ is then given by the equation:

$$
E_{n c}=E_{d}-E_{s}
$$

The excess energy available for storage charging $E_{c}$ can then be calculated using Equation (9):

$$
E_{c}=\frac{\left(E_{i n v, A C}-E_{S}\right)}{\eta_{i n v}}
$$

\section{Storage formulas}

Battery state of charge is the percentage of energy that is present in the battery with respect to its capacity, this can be modelled because the $E_{n c}$ and $E_{c}$ is already known from Equation (8) and (9). If there is excess energy for storage, then the energy that goes into the storage $\mathrm{E}_{\mathrm{s}}$ at the end of that hour is given according to (Hamad and Alsaad, 2010):

$$
E_{s}=E_{s, 0}+\eta_{c} E_{c}
$$

where $E_{c}$ is the available charging energy, $E_{s, 0}$ is the original energy content at the start of the simulated hour and $\eta_{c}$ is the charging efficiency. On the other hand, if there is still demand and discharging occurs during that hour, then its energy content at the end of the hour is:

$$
E_{s}=E_{s, 0}-E_{n c} / \eta_{d}
$$

Where $\eta_{d}$ is the discharging efficiency and $E_{n c}$ is the demand not yet covered calculated in Equation (8). The charging $\eta_{c}$ and discharging $\eta_{d}$ efficiency of a lead acid battery is approximately $80-90 \%$ (IMS, 2011). The $E_{S}$ can then be derived from the two conflicting equations (10) and (11); each is correct depending on the situation. The formula for the energy in the battery $E_{s}$ in the end of the simulated hour is given by the equation:

$$
E_{s}=\left\{\begin{array}{cl}
E_{s, 0}+\eta_{c} E_{c}-\frac{E_{n c}}{\eta_{d}}, & \left(E_{s, 0}+\eta_{c} E_{c}-\frac{E_{n c}}{\eta_{d}}\right)>0 \\
E_{\max }, & \left(E_{s, 0}+\eta_{c} E_{c}-\frac{E_{n c}}{\eta_{d}}\right)>E_{\max } \\
0, & \text { otherwise }
\end{array}\right.
$$


Then the SoC is given by the equation:

$$
\operatorname{SoC}[\%]=\frac{E_{s}}{E_{\max }} \times 100[\%]
$$

Where $E_{S}$ is the energy inside the battery, $E_{\max }$ is the capacity of the battery and SoC is the state of charge of the battery in percentage.

Nonetheless the above formulas just show the energy level of the battery, to find the nominal value of the energy that has been added to storage $E_{a}$, the equation below can be used.

$$
E_{a}=E_{s, \text { actual }}-E_{s, 0}
$$

\section{Energy allocation}

Firstly, in the whole energy system there are multiple ways the energy in the system is allocated. Energy to fulfil demand directly and energy to storage has already been discussed in Section 0 and 0 respectively. The remaining pathways of energy: demand covered by battery and excess energy is explored below.

Demand covered by the battery $E_{d, b a t t}$ occurs when there is demand and insufficient energy from PV is generated thus energy is taken from the battery and is given by the equation:

$$
E_{d, \text { batt }}=\left\{\begin{aligned}
\left(E_{s, 0}-E_{s, \text { actual }}\right) \eta_{\text {inv }} \eta_{d}, & \text { SoC }_{t}<\text { SoC }_{0} \\
0, & \text { Otherwise }
\end{aligned}\right.
$$

Where $S o C_{t}$ is the current $\mathrm{SoC}$ and $S o C_{0}$ is the previous SoC, excess energy is then found by simply subtracting all the other energy pathways.

$$
E_{\text {excess }}=E_{c-} E_{a}
$$

\section{Battery charging and dumped energy}

Using the amount of excess energy that was calculated using formula ....the number of batteries charged $n_{\text {batt }}$ can then be found.

$$
n_{\text {batt }}= \begin{cases}\frac{E_{\text {excess }}}{E_{\text {batt }} / \eta_{c}}, & \frac{E_{\text {excess }}}{E_{\text {batt }} / \eta_{c}}<\frac{P_{\text {charger }}}{P_{\text {batt,max }}} \\ \frac{P_{\text {charger }}}{P_{\text {batt }, \text { max }}}, & \text { otherwise }\end{cases}
$$

$E_{\text {batt }}$ is the capacity of the battery; $\eta_{c}$ is the charging capacity; $P_{\text {charger }}$ is the nominal power of the charger; $P_{b a t t, \max }$ is the maximum power that the battery can receive to charge, which is the maximum charging current at $1 \mathrm{C}$ multiplied by the nominal voltage of the battery.

Dumped energy $E_{\text {dump }}$ is therefore the amount of energy left is given by the equation:

$$
E_{\text {dump }}=E_{\text {excess }}-n_{\text {batt }} \times\left(\frac{E_{\text {batt }}}{\eta_{c}}\right)
$$




\section{Appendix 2. Modelling tool dashboard and calculation spreadsheet}

\section{Modelling Dashboard}

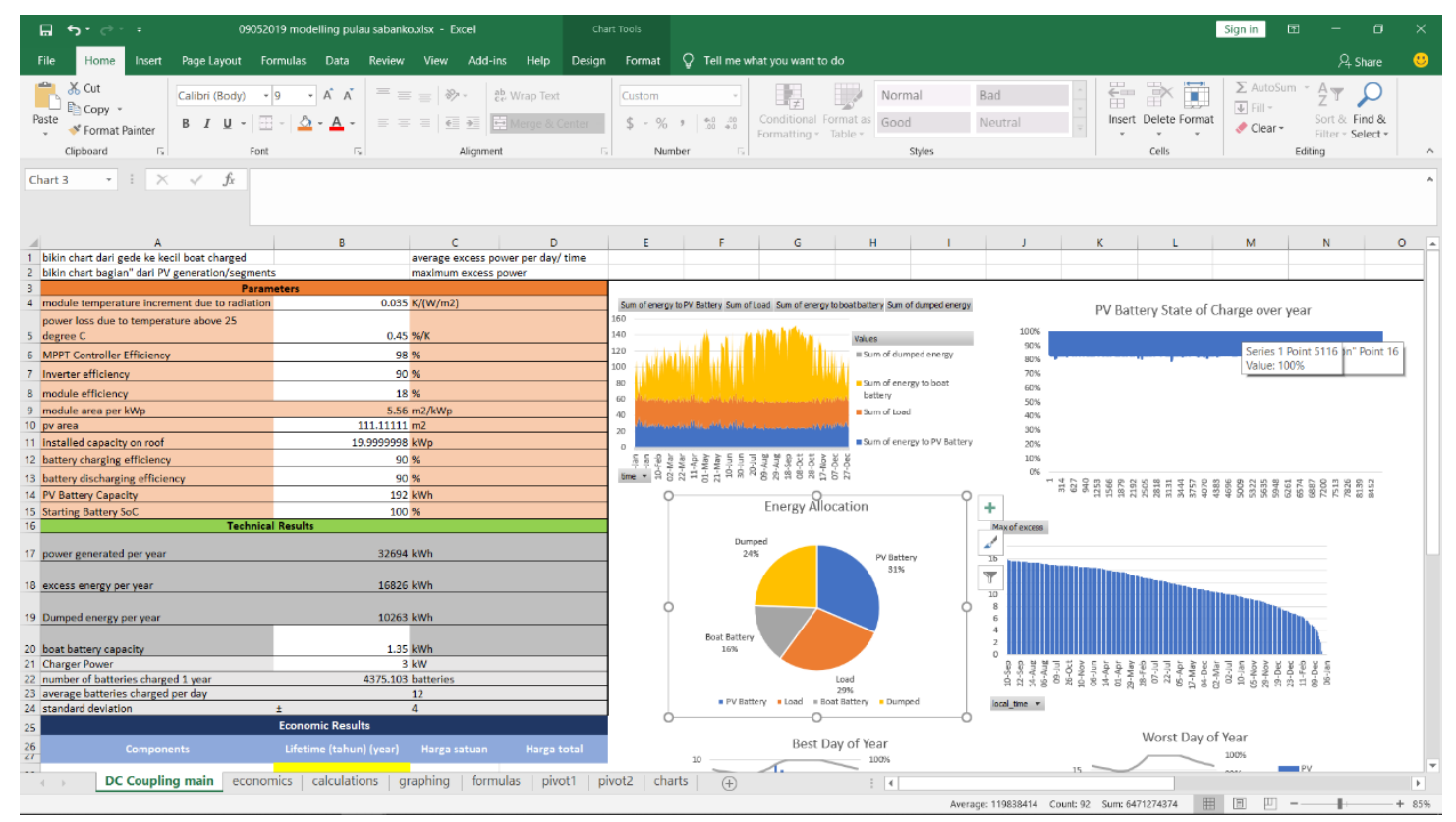

\section{Modelling calculation}

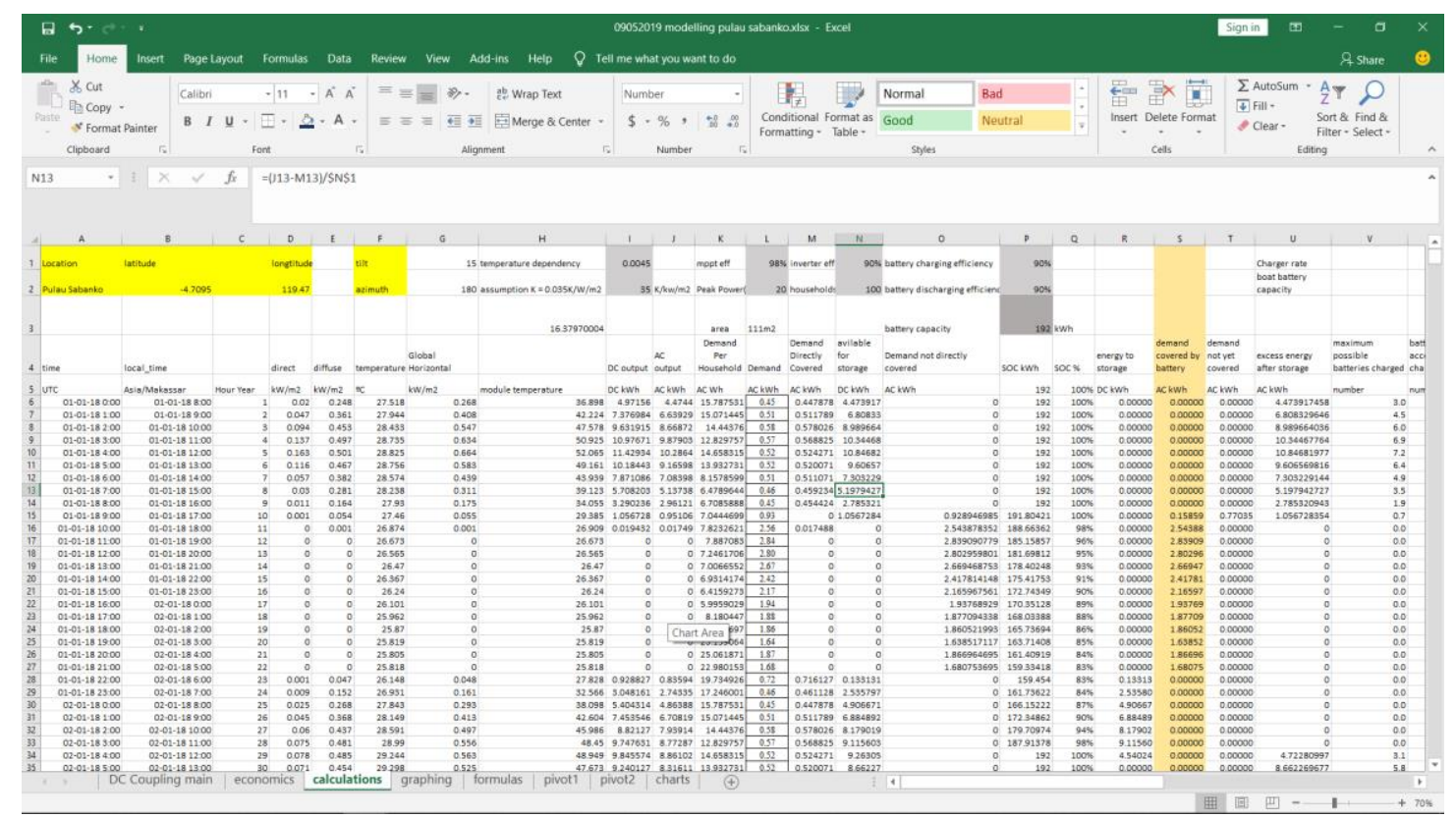




\section{Appendix 3. Project Cash Flow}

Charging and Battery renting business life cycle cost yearly cash flow.

(Values are in Rp. 000.-)

\begin{tabular}{|c|c|c|c|c|c|c|c|}
\hline Year & VMT wages & $\begin{array}{c}\text { Shared } \\
\text { Replacement } \\
\text { costs }\end{array}$ & $\begin{array}{c}\text { Charging } \\
\text { system + } \\
\text { Battery } \\
\text { Repalcement }\end{array}$ & Other OpEx & $\begin{array}{l}\text { Overall Discounted } \\
\text { Annual Costs }\end{array}$ & $\begin{array}{l}\text { Energy Produced } \\
\qquad(\mathrm{kWh})\end{array}$ & $\begin{array}{c}\text { Discounted energy } \\
\text { produced (kWh) }\end{array}$ \\
\hline 1 & 4,944 & - & - & 1,472 & 6,416 & 8,377 & 7,978 \\
\hline 2 & 4,850 & - & - & 1,444 & 6,294 & $8,343.5$ & 7,568 \\
\hline 3 & 4,757 & - & - & 1,416 & 6,174 & 8,293 & 7,164 \\
\hline 4 & 4,667 & - & - & 1,389 & 6,056 & 8,244 & 6,782 \\
\hline 5 & 4,578 & 477 & - & 1,363 & 6,418 & 8,194 & 6,420 \\
\hline 6 & 4,491 & - & - & 1,337 & 5,828 & 8,145 & 6,078 \\
\hline 7 & 4,405 & - & - & 1,311 & 5,717 & 8,096 & 5,754 \\
\hline 8 & 4,321 & - & - & 1,287 & 5,608 & 8,048 & 5,447 \\
\hline 9 & 4,239 & - & - & 1,262 & 5,501 & 7,999 & 5,156 \\
\hline 10 & 4,158 & 78,111 & 221,113 & 1,238 & 304,621 & 7,951 & 4,881 \\
\hline 11 & 4,079 & - & - & 1,214 & 5,293 & 7,904 & 4,621 \\
\hline 12 & 4,001 & - & - & 1,191 & 5,193 & 7,856 & 4,375 \\
\hline 13 & 3,925 & - & - & 1,169 & 5,094 & 7,809 & 4,141 \\
\hline 14 & 3,850 & - & - & 1,146 & 4,997 & 7,762 & 3,920 \\
\hline 15 & 3,777 & 393 & - & 1,124 & 5,295 & 7,716 & 3,711 \\
\hline 16 & 3,705 & - & - & 1,103 & 4,808 & 7,669 & 3,513 \\
\hline 17 & 3,635 & - & - & 1,082 & 4,717 & 7,623 & 3,326 \\
\hline 18 & 3,565 & - & - & 1,061 & 4,627 & 7,578 & 3,149 \\
\hline 19 & 3,497 & - & - & 1,041 & 4,539 & 7,532 & 2,981 \\
\hline 20 & 3,431 & - & - & 1,021 & 4,452 & 7,487 & 2,822 \\
\hline Total & 82,876 & 78,982 & 221,113 & 24,673 & 407,644 & & 99,788 \\
\hline
\end{tabular}

